\title{
Etiology, prevalence, and treatment of dry eye disease
}

This article was published in the following Dove Press journal:

Clinical Ophthalmology

3 July 2009

Number of times this article has been viewed

\section{Johnny L Gayton}

Eyesight Associates, Warner Robins, GA, USA
Correspondence: Johnny Gayton Eyesight Associates, 216 Corder Road, Warner Robins, GA 31088 , USA

Tel + I 478-923-5872

Fax + I 478-929-6266

Email jlgayton@aol.com
Purpose: This review article examines the prevalence, etiology, and current therapies of dry eye disease, with special focus on postmenopausal women.

Method: A systematic literature search utilizing MEDLINE was conducted to identify peerreviewed articles related to dry eye published prior to September 2008. The terms "dry eye" and "women" were searched in combination with one or more of the following words or phrases: prevalence, postmenopausal, etiology, risk factors, therapy, medications, surgery, tear film, and quality of life. Articles were selected based on their direct applicability to the subject matter. A manual search was also conducted based on citations in the published literature.

Results: Epidemiologic studies identified prevalence rates ranging from $7 \%$ in the United States to 33\% in Taiwan and Japan. Risk factors include advanced age, female sex, smoking, extreme heat or cold weather conditions, low relative humidity, use of video display terminals, refractive surgery, contact lens wear, and certain medications.

Conclusion: The last decade has brought about a better understanding of the etiology of dry eye disease. New therapies that can alleviate the signs and symptoms of dry eye disease and, consequently, improve the quality of life of dry eye patients are available in the market.

Keywords: dry eye disease, etiology, prevalence, postmenopausal women

\section{Overview}

Dry eye disease (DED) is one of the most frequently encountered ocular morbidities. Twenty-five percent of patients who visit ophthalmic clinics report symptoms of dry eye, making it a growing public health problem and one of the most common conditions seen by eye care practitioners. ${ }^{1}$ Historically, the term "Keratoconjunctivitis sicca" can be attributed to the Swedish ophthalmologist Henrik SC Sjögren. ${ }^{2}$ He was the first to refer to the triad of Keratoconjunctivitis sicca, dry mouth, and joint pain, which occurs mainly in women $(90 \%$ of the cases) (www.sjogrens.org/), and in 1950 Andrew De Roetth introduced the term "dry eye". ${ }^{3}$ For many decades, DED was thought to be limited to dryness of the eyes due to reduction of the aqueous phase of the tear film. In 1995, DED was defined as a complex multifaceted group of medical and ocular diseases that is due to decreased tear production and/or increased tear evaporation. ${ }^{4}$ In 2007, the International Dry Eye Workshop (DEWS) revised the original definition and classification scheme of DED and developed a new definition, as well as a three-part classification of DED based on etiology, mechanism, and severity of the disease. ${ }^{5}$ The new definition of dry eye is "Dry eye is a multifactorial disease of the tears and ocular surface that results in symptoms of discomfort, visual disturbance, and tear 
film instability with potential damage to the ocular surface. It is accompanied by increased osmolarity of the tear film and inflammation of the ocular surface." Additionally, DED can be categorized as episodic or chronic. Episodic dry eye occurs when environmental or visual tasks with reduced blinking overwhelm the stability of the tear and produce symptomatic dry eye. Chronic dry eye, although aggravated by the same environmental conditions, persists continuously with symptoms and possible damage to the ocular surface. ${ }^{6}$ Because the tear film in dry eye patients is unstable and incapable of maintaining the protective qualities that are necessary for its structure and function, patients experience the discomfort symptoms associated with dry eye, which are burning, stinging, grittiness, foreign body sensation, tearing, ocular fatigue, and dryness. ${ }^{7}$ Patients may complain of symptoms of dry eye in the presence or absence of signs of the disease. Additionally, dry eye may be diagnosed based only on the signs observed by a healthcare professional in the absence of symptoms/complaints by the patients.

\section{Demographics of dry eye}

Dry eye disease is seen with increased prevalence in patients with autoimmune diseases, ${ }^{8}$ which affect approximately $8 \%$ of the population, of whom $78 \%$ are women. ${ }^{9}$ Dry eye disease also affects postmenopausal women ${ }^{10}$ and the elderly. ${ }^{11,12}$ The prevalence of DED is estimated to be $7.4 \%$ to $33.7 \%{ }^{12,13}$ depending on which study is cited, how the disease is diagnosed, and which population is surveyed. The Beaver Dam population-based study found the DED prevalence rate to be $14 \%$ in adults 48 to 91 years of age. ${ }^{11}$ The study also found that DED affects more women than men $(16.7 \%$ versus $11.4 \%$, respectively). Reliable epidemiological studies from the large Women's Health Study and Physician's Health Study indicate that the prevalence of symptomatic dry eye in the United States is about 7\% in women and 4\% in men over the age of 50 years. ${ }^{10}$ These numbers translate into approximately 3.2 million women and 1.05 million men with DED in the United States. ${ }^{14}$ Estimates of those affected by DED of any severity amount to approximately 20 million or more in the United States alone. ${ }^{15}$ Likewise, international epidemiological studies report similar or higher rates around the world. The prevalence of DED is approximately $7.4 \%$ in Australia, with significant increase of prevalence in older patients and a significant decrease of tear production in women 50 to 59 years of age. ${ }^{13}$ In Indonesia, dry eye prevalence is approximately $27.5 \%$, with increased prevalence associated with age, cigarette smoking, and pterygium. ${ }^{16}$ In Taiwan, the prevalence of DED is $33.7 \%$ in a tested elderly population, with significantly more women reporting dry eye symptoms than men. ${ }^{12}$ The prevalence of dry eye is also estimated at $25 \%$ in Canada ${ }^{17}$ and $33 \%$ in Japan. ${ }^{18}$ It is worth noting that the prevalence and incidence of DED, in the clinical setting, may also be under-reported, as patients may fail to recognize the symptoms of DED or do not report the problem to a physician.

\section{Etiology and risk factors of dry eye disease}

The last decade brought about a significant improvement in the understanding of the etiology and pathogenesis of DED. One major advance in the understanding of DED is the recognition of the two distinct components of the disease-tear evaporation and insufficient tear production-and their roles individually or concomitantly in DED. ${ }^{19}$ Another improvement is the identification of tear film instability as a common feature of the various stages of DED and the realization that the thickness of the lipid layer might determine the stability of the tear film. ${ }^{20}$ Additionally, appreciation of the role of inflammation in DED was one of the most important factors that aided in the understanding and treatment of DED. The findings of the association of inflammation with reduced tear secretion and subsequent damage to the ocular surface led to the proposal of a unified concept of DED. ${ }^{21}$

Several risk factors for the development of DED have been identified repeatedly in epidemiological studies (Figure 1), such as increasing age and female sex (particularly postmenopausal women). In clinical experience, menopausal and postmenopausal women both tend to have dry eye symptoms; this can be attributed to the significant decrease of tear production around the sixth decade of life in women. ${ }^{22}$ Hormonal studies suggest that sex hormones influence ocular surface conditions through their effects on tear secretions, meibomian gland function, and conjunctival goblet cell density. Conner and colleagues ${ }^{23}$ pointed out that women who were taking oral contraceptives had significantly higher goblet cell density than those who were not taking oral contraceptives. Krenzer and colleagues reported that chronic androgen deficiency is associated with meibomian gland dysfunction. Schaumberg and colleagues and Uncu and colleagues reported that postmenopausal women who use hormonal replacement therapy (HRT) have a higher prevalence of DED compared with those who have never used HRT. ${ }^{24-26}$ This was particularly true for women who used estrogen alone. Likewise, Smith and colleagues noted that women with primary ovarian failure developed clinically significant DED. ${ }^{27}$ 


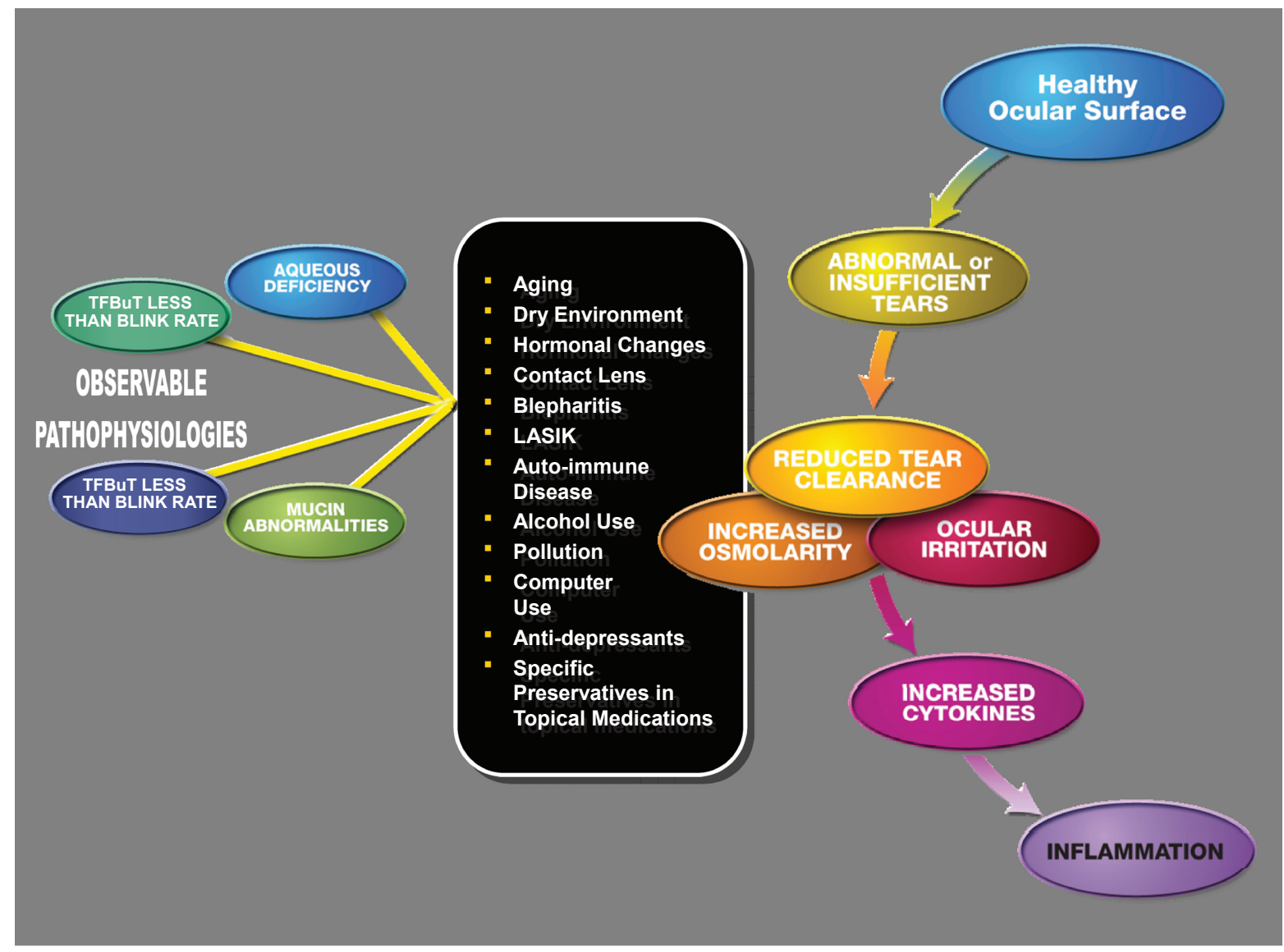

Figure I Dry eye cascade. Causes and contributing factors of abnormal tear film.

Abbreviations: TFBuT, tear film break-up time; LASIK, laser-assisted in situ keratomileusis.

Other factors that precipitate and/or exacerbate DED include long-term contact lens wear, as it desensitizes the cornea over years of contact lens stimulation. Certain systemic medications, such as some antihistamines and antidepressants, have drying side effects, which can exacerbate or lead to dry eye. ${ }^{7}$ For several months after refractive surgery such as laser-assisted in situ keratomileusis (LASIK) or photorefractive keratectomy (PRK), patients may experience significant dry eye due to the severing of the corneal nerves during surgery. ${ }^{28,29}$

Furthermore, DED can be influenced through various daily activities and social and dietary habits such as smoking, which increases the frequency of DED, ${ }^{16}$ and the dietary intake of omega-3 fatty acids, which reduces the incidence of DED. ${ }^{30}$ Extended visual tasking during computer use, television watching, and prolonged reading provoke symptoms of dry eye. ${ }^{31}$ Moreover, Schindelar and colleagues reported on the diurnal variations in the symptoms of dry eye..$^{32}$ The exacerbation of the symptoms was dependent on the activities done at the time. For example, patients complaining of exacerbation of dry eye symptoms in the evening had reported driving, reading, and watching television in the evening.

\section{Effects of the climate on dry eye disease}

In addition to the above-mentioned etiologies and risk factors, climate and environmental challenges, such as relative humidity $(\mathrm{RH})$, indoor environment, pollution, air travel, and extreme temperatures, among others, play a role in the prevalence of DED. A number of studies have shown an association between low RH and increased prevalence of DED, and that an increase of RH will result in fewer complaints of dry eye. Both RH and temperature influence the overall thermal climate and its effect on the precorneal tear film, and, thus, dry eye symptoms. Low RH conditions (office environment, air conditioned cars, airplane cabins, and extreme hot or cold weather) negatively impact the tear film, whereas an increase of RH leads to a more stable tear film, and, thus, more protection against desiccation of the eye. ${ }^{33,34}$ Kjæregaard and colleagues ${ }^{35}$ reported that low ambient temperature and high $\mathrm{RH}$ are associated with more tear film 
stability than low RH and high temperature..$^{35}$ Therefore, it is recommended that the indoor air should be "dry and cool," with a RH of about $40 \%$, which is better for the eyes than a RH below 30\%. ${ }^{36}$ Outdoor air quality and temperature also affect tear film stability. Exposure to sun, dust, and wind exacerbate or precipitate DED. ${ }^{37}$ In the Women's Health Study, Schaumberg and colleagues reported that women from the southern United States had a high prevalence of DED. ${ }^{25}$ These indoor and outdoor factors can lower the quality of life and productivity of dry eye patients.

\section{Effect of dry eye on the quality of life}

The burden of DED to the patient is not trivial. Studies suggest that DED can have a considerable impact on visual function, daily activities, social and physical functioning, workplace productivity, direct and indirect cost of the disease, and quality of life (QOL). ${ }^{38,39}$ A reduction in QOL is inevitable when the symptoms of dry eye occur, whether they are mild, transient irritations or persistent symptoms. Schiffman and colleagues used utility assessment scores to quantify the QOL of DED patients. ${ }^{40} \mathrm{~A}$ perfect health has a utility score $=1.0$, whereas death has a utility score $=0$. The closer the utility score is to 1.0, the better the QOL. Compared with other diseases, mild dry eye had a utility score of 0.81 , compared with a utility score of 0.89 for psoriasis.
Moderate dry eye had a utility score of 0.78 , which is in the same range reported for moderate angina (0.75). Severe dry eye and dry eye requiring tarsorrhaphy had utility scores of 0.72 and 0.62 , respectively. The former score corresponds to class III/IV angina (0.71) and the latter is worse than disabling hip fracture $(0.65)$. These low utility scores emphasize the burden and negative impact of DED on QOL, and, in a way, may explain why in the United States alone, approximately 7 to 10 million Americans use artificial tear preparations, with consumer spending estimated to be US\$320 million per year. ${ }^{41}$

\section{Physiology and function of the tear film}

The healthy tear film contains a mixture of lipid, aqueous, and mucin (Figure 2). Prior to 1994, it was believed that the tear film was a sandwiched layer of lipid, aqueous, and mucin. ${ }^{42} \mathrm{~A}$ more recent model of the tear film is described as an interactive hydrated mucin gel, with lipid present not only on the surface of the tear film, but also associated with proteins that are distributed throughout the gel. ${ }^{43}$ The moisture of the eye, which is essential for optical and physiological reasons, is maintained by the secretions of lipid, aqueous humor, and mucous. Lipids prevent evaporation and stabilize the tear film. Any disruption of oil secretion results in increased evaporation and destabilization of the

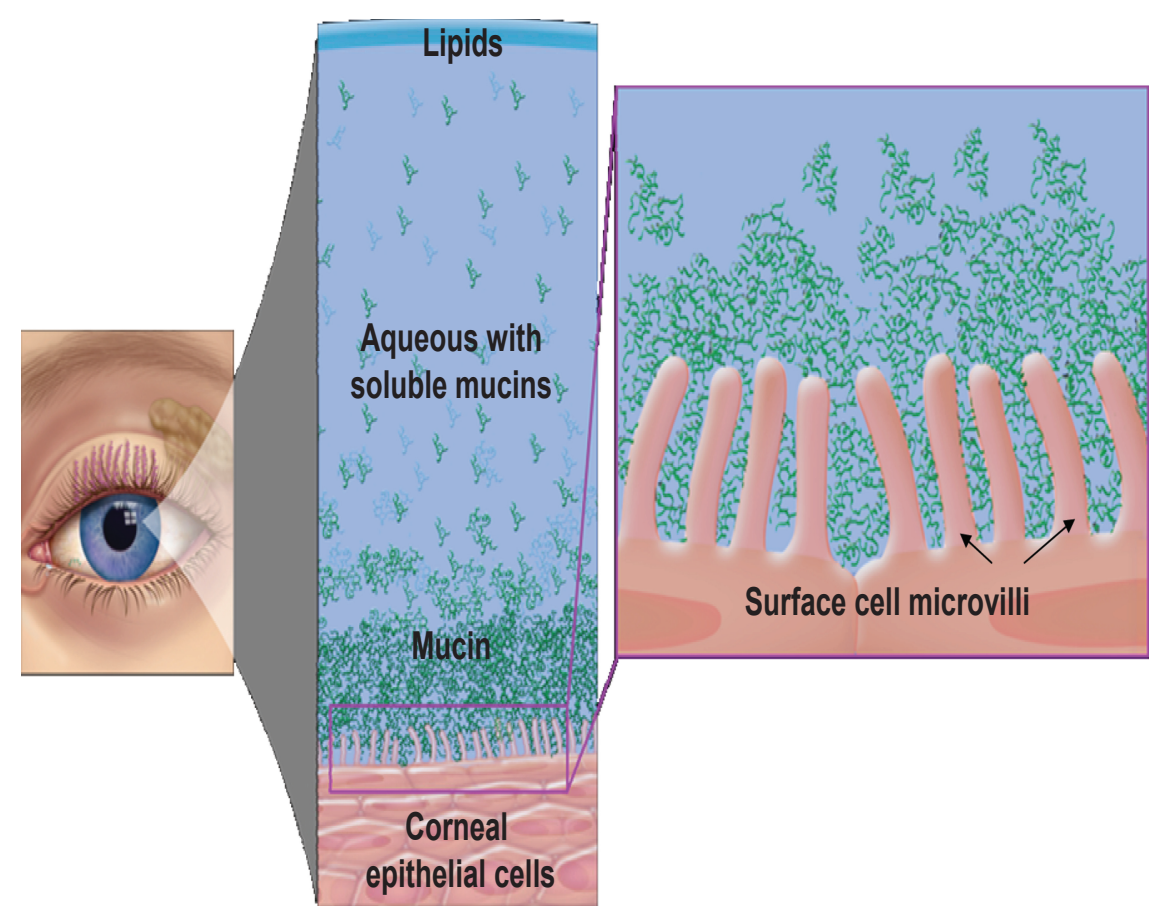

Figure 2 Healthy tear film with lipid, aqueous, and mucin layers and healthy ocular surface with intact microvilli. 
tear film, and, subsequently, DED. The aqueous layer makes up the bulk of the tear film and provides essential nutrients and oxygen to the avascular cornea, assists in the removal of metabolic wastes and debris, protects the ocular surface by carrying bacteriolytic enzymes and proteins, and provides the ocular surface with moisture. Reduced aqueous secretion due to decreased production or increased evaporation leads to DED. Mucin creates a smooth hydrophilic barrier to the corneal epithelium for wetting of the ocular surface and protection from desiccation. Reduction in mucin secretion due to inflammation or trauma reduces tear film stability, potentially causing severe DED. ${ }^{7}$ In addition, inferior lid laxity, ectropic lid margin, incomplete lid closure, decreased blinking frequency, or incomplete blinking lead to functional dry eye despite normal tear film layers. ${ }^{44}$ A compromised tear film can lead to damage of the corneal and conjunctival epithelium with the resultant discomfort symptoms associated with dry eye (Figure 3 ). In general, all the intrinsic and extrinsic etiology and risk factors that lead to or exacerbate DED lead to unstable tear film due to the disruption of the structure or function of one or more of its layers. Clinicians usually rely on patients' history along with other tests to diagnose DED, such as subnormal Schirmer testing, supravital staining of the ocular surface, and reduced tear film break-up time (TFBuT), among others.

\section{Therapeutic options for dry eye disease}

The first step in managing the disease is to identify the underlying etiology and to try to eliminate it and/or treat it. Afterward, and regardless of the etiology, the mainstay firstline therapy is external augmentation of the tear film with topically administered artificial tear substitutes. Currently, there are numerous formulations on the market attempting to enhance tear film stability and increase TFBuT; however, many have been found to only temporarily relieve the symptoms of dry eye ${ }^{45}$ rather than to heal the ocular surface or treat the underlying cause of the disease. Artificial tears are typically buffered solutions that contain electrolytes, surfactants, preservatives (not all formulations), and a viscosity agent that is intended to increase the residency time of the drop. ${ }^{46}$ Although most artificial tears contain similar ingredients, they differ in the type of lubricant used, in their chemical properties, and in the type (or the lack thereof) of the preservative used. ${ }^{47}$ A review of the various formulations is discussed and presented by Murube and colleagues. ${ }^{48,49}$
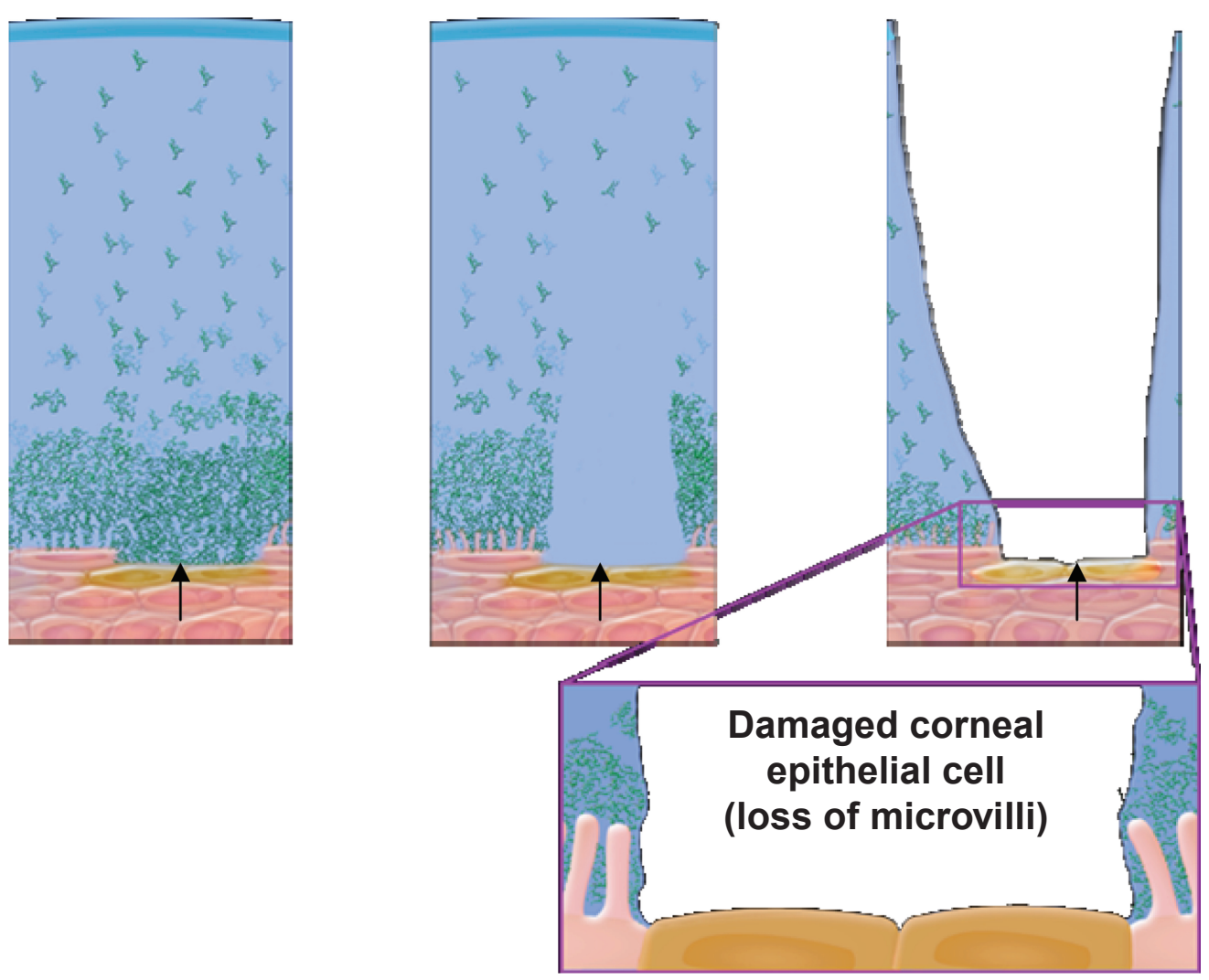

Figure 3 Progressive damage of corneal surface cells (lost microvilli) due to unhealthy tear film. 
Recent technologies in artificial tear formulations have focused on improving the shortfall (transient nature) of earlier formulations. The main role of osmolytes added to artificial tear formulations, such as in Optive ${ }^{\circledR}$ (Allergan, Inc., Irvine, CA, USA), is to provide osmoprotection of the ocular surface against the high osmolarity of the tear film present in DED. When used concomitantly with cyclosporine $0.05 \%$ (Restasis $^{\circledR}$, Allergan, Inc.), Optive ${ }^{\circledR}$ improved TFBuT. ${ }^{50}$ Addition of lipids to artificial tears aims to enhance tear film stability. Soothe ${ }^{\circledR}$ (Bausch and Lomb, Rochester, NY, USA), which is a metastable lipid emulsion, increased lipid layer thickness after 1 minute of instillation and improved dry eye symptoms in patients after application for one month. ${ }^{51}$ Another technology that protects the ocular surface by stabilizing the tear film and increasing the TFBuT is the hydroxypropyl (HP) guar-based molecule present in Systane ${ }^{\circledR}$ (Alcon Laboratories, Inc., Fort Worth, TX, USA). Original Systane ${ }^{\circledR}$ works well as a monotherapy to prolong TFBuT and protect the ocular surface and as an adjunct therapy to enhance the effect of cyclosporine $A$ in the treatment of DED. ${ }^{52,53}$ Systane $^{\circledR}$ Ultra (Alcon Laboratories, Inc.) is the newest addition to the market. The $\mathrm{pH}$ of Systane ${ }^{\circledR}$ Ultra is 7.9, which allows HP-Guar and borate to form a loosely cross-linked matrix in the bottle. The addition of sorbitol in this formulation controls the cross-linking, delivering the solution to the eye while providing the lasting properties of a gel. This results in prolonged comfort without a momentary blurring of vision. Moreover, Systane ${ }^{\circledR}$ Ultra works in concert with the natural divalent ions in the tear film (calcium, zinc, and magnesium), which strengthen the dynamic cross-linking of HP-Guar and borate and allow the tear film to mimic that of healthy eyes; this is important since, on average, there are 7,000 to 10,000 blinking events every day, and the tear film must remain stable between blinks.

Restasis ${ }^{\circledR}$ is the only prescription drug in the United States for the treatment of DED. It is indicated for patients whose tear production is presumed suppressed due to ocular inflammation; as such, it targets chronic inflammation-related DED. Restasis $^{\circledR}$ statistically significantly increased Schirmer test scores in $15 \%$ of the patients, whereas increased tear production was not seen in patients using topical anti-inflammatory drugs or punctal plugs ${ }^{54}$ The package insert states "Restasis ${ }^{\circledR}$ can be used concomitantly with artificial tears allowing a 15-minute interval between products." Restasis ${ }^{\circledR}+$ original Systane ${ }^{\circledR}$ was statistically significantly better than Restasis ${ }^{\circledR}+$ Refresh Tears ${ }^{\circledR}$ (Allergan, Inc.), another artificial tear formulation; in fact, the original Systane ${ }^{\circledR}$ alone was better than Restasis ${ }^{\circledR}+$ Refresh Tears ${ }^{\circledR}$ at increasing TFBuT 6 months after initiation of therapy. ${ }^{53}$ Therefore, the appropriate choice of concomitant therapy used with Restasis ${ }^{\circledR}$ will have significant effects on outcome measures.

\section{Clinical perspective}

Eye care practitioners now recognize DED and its associated complications as not only one of the most common conditions seen in the office, but also one that significantly affects QOL. In the past, lectures about DED were given on the last day of medical conferences to nearly empty rooms, but this is not the case any longer. Once the medical and pharmaceutical communities recognized the impact DED has on people's daily lives and on patients undergoing ocular surgery, several treatment modalities and options were made available. It is important to note that because DED is highly prevalent in women, who make most of the healthcare decisions for their families, when an eye care provider treats a woman's DED, additional family members frequently come to the practice seeking help.

It is imperative that clinicians take a comprehensive approach in managing DED and its associated conditions by treating the various potential contributing factors of the disease. First, environmental changes, such as advising patients to wear glasses that decrease evaporation of tears; adjusting air vents at home, in the office, and in cars; adjusting ceiling fans; and controlling humidity, should be recommended. Second, patients should be advised to discontinue or avoid exposure to tobacco smoke, which destabilizes the tear film and decreases tear production. Third, patients should be encouraged to make dietary changes as well, such as reducing alcohol ingestion because it causes dehydration and exacerbates DED. Omega-3 oils, fish oil, and flaxseed oil can improve the tear film and decrease the inflammation associated with DED; therefore, patients should be advised to add these elements to their diets. Fourth, avoiding systemic diuretics and antihistamines, if possible, can significantly improve DED. Finally, because benzalkonium chloride, the most frequently used preservative in ophthalmic solutions, destabilizes the tear film and damages epithelial cells, it is prudent to encourage patients to use as few topical medications as possible. Clinicians may opt to change patients' prescription to preservative-free formulations, such as Vigamox ${ }^{\circledR}$ or unit-dose Timolol ${ }^{\circledR}$, or formulations with an alternative preservative, such as that found in Travatan $Z^{\circledR}$, Alphagan ${ }^{\circledR}$ P, or Systane ${ }^{\circledR}$ Ultra whenever possible. When a patient is not responding well to environmental and lifestyle changes, and/or the use of artificial 
tears, Restasis ${ }^{\circledR}$ and a course of topical steroids should be added to the artificial tears regimen. Steroids help control DED-associated inflammation, but they should not be used long term because of their possible role in elevating IOP and causing cataracts. The two main issues associated with the use of Restasis ${ }^{\circledR}$ are burning, which is very significant in some patients, and the relatively long onset of action that does not provide immediate relief. Restasis ${ }^{\circledR}$ is very useful, however, in long-term control of DED. Restasis ${ }^{\circledR}$ is to be used twice daily and be supplemented with artificial tears. In a small percentage of patients, these combinations are sometimes insufficient. In these cases, punctal plugs or cautery should be considered.

Because DED is so prevalent and has such a significant impact on finances and quality of life, many pharmaceutical companies are working on other treatments options, some of which will be available in coming months. The ability of a physician to alleviate suffering, enhance QOL, and improve surgical outcomes in the vast majority of DED patients results in happier patients and better practices.

\section{Conclusion}

DED is a prevalent, multifactorial disease that is particularly frequent in elderly patients and women, especially menopausal and postmenopausal women. DED can be episodic with transient signs and symptoms or chronic with persistent signs and symptoms. DED has a significant impact on visual function that can negatively impinge on the patient's quality of life and productivity. Selection of the appropriate topical therapy should include consideration of the underlying cause of the disease, age and sex of the patient, concomitant medications such as antihistamines or hormonal replacement therapy, and presence or absence of inflammatory eye disease. As we continue to learn about DED, and with the emergence of new therapies, the quality of life of women, elderly patients, and all other patients suffering from DED will be improved.

\section{Acknowledgment}

The author thanks Heba Costandy, MD, MS for medical writing and editing contributions.

\section{Disclosures}

Financial support: This was an investigator-initiated research. Dr Johnny Gayton is on the speaker's bureau for Alcon Laboratories, Inc., Fort Worth, TX, USA. The author has no commercial or proprietary interest in any of the products mentioned in this article.

\section{References}

1. O'Brien PD, Collum LM. Dry eye: diagnosis and current treatment strategies. Curr Allergy Asthma Rep. 2004;4:314-319.

2. Sjögren HSC. Zur Kenntnis der Keratoconjunctivitis sicca (Keratitis filiformis bei Hypofunktion der Tränendrüsen). Acta Ophthalmol. 1933;Supp. II:1-151 Copenhagen.

3. Murube J. Andrew de Roetth (1893-1981): dacryologist who introduced the term dry eye. Ocul Surf. 2004;2:225-227.

4. Lemp MA. Report of the National Eye Institute/industry Workshop on clinical trials in dry eye. CLAO J. 1995;21:221-232.

5. International Dry Eye Workshop (DEWS). The definition and classification of dry eye disease: report of the Definition and Classification Subcommittee of the International Dry Eye Workshop. Ocul Surface. 2007;5:75-92.

6. Foulks GN. Pharmacological management of dry eye in the elderly patient. Drugs Aging. 2008;25:105-118.

7. Terry MA. Dry eye in the elderly. Drugs Aging. 2001;18:101-107.

8. Fox RI, Howell FV, Bone RC, et al. Primary Sjögren's syndrome: clinical and immunopathologic features. Semin Arthritis Rheumatol. 1984;14:77-105.

9. Fairweather D, Frisancho-Kiss S, Rose NR. Sex differences in autoimmune disease from a pathological perspective. Am J Pathol. 2008;173:600-609.

10. Schaumberg DA, Sullivan DA, Buring JE, et al. Prevalence of dry eye syndrome among US women. Am J Ophthalmol. 2003;136:318-326.

11. Moss SE, Klein R, Klein BE. Prevalence of and risk factors for dry eye syndrome. Arch Ophthalmol. 2000;118:1264-1268.

12. Lin PY, Tsai SY, Cheng CY, et al. Prevalence of dry eye among an elderly Chinese population in Taiwan: The Shihpai eye study. Ophthalmology. 2003;110:1096-1101.

13. McCarty CA, Bansal AK, Livingston PM, et al. The epidemiology of dry eye in Melbourne, Australia. Ophthalmology. 1998;105:1114-1119.

14. Schaumberg DA, Sullivan DA, Dana MR. Epidemiology of dry eye syndrome. Adv Exp Biol Med. 2002;506:989-998.

15. Market Scope. Report on the global dry eye market. St. Louis, MO. 2004.

16. Lee AJ, Lee J, Saw S-M, et al. Prevalence and risk factors associated with dry eye symptoms: a population based study in Indonesia. $\mathrm{Br} \mathrm{J}$ Ophthalmol. 2002;86:1347-1351.

17. Doughty MJ, Fonn D, Richeter D, et al. A patient questionnaire approach to estimating the prevalence of dry eye symptoms in patients presenting to optometric practices across Canada. Optom Vis Sci. 1997;74:624-631.

18. Shimmura S, Shimazaki J, Tsubota K. Results of a population-based questionnaire on the symptoms and lifestyles associated with dry eye. Cornea. 1999;18:408-411.

19. Perry HD, Donnenfeld ED. Dry eye diagnosis and management in 2004 Curr Opin Ophthalmol. 2004;15:229-304.

20. Isreb MA, Greiner JV, Korb DR, et al. Correlation of lipid layer thickness measurements with fluorescein tear film break-up time and Schirmer's test. Eye. 2003;17:79-83.

21. Stern ME, Beuerman RW, Fox RI, et al. A unified theory of the role of the ocular surface in dry eye. Adv Exp Med Biol. 1998;438:643-651.

22. Lambert DW, Foster CS, Perry HD. Schirmer test after topical anesthesia and the tear meniscus height in normal eyes. Arch Ophthalmol. 1979;97:1082-1085.

23. Connor CG, Flockencier LL, Hall CW. The influence of gender on the ocular surface. J Am Optom Assoc. 1999;70:182-186.

24. Krenzer KL, Dana MR, Ullman MD, et al. Effect of androgen deficiency on the human meibomian gland and ocular surface. J Clin Endocrinol Metab. 2000;85:4874-4882.

25. Schaumberg DA, Buring JE, Sullivan DA, et al. Hormone replacement therapy and dry eye syndrome. JAMA. 2001;286:2114-2119.

26. Uncu G, Avci R, Uncu Y, et al. The effects of different hormone replacement therapy regimens on tear function, intraocular pressure and lens opacity. Gynecol Endocrinol. 2006;22:501-550. 
27. Smith JA, Vitale S, Reed GF, et al. Dry eye signs and symptoms in women with premature ovarian failure. Arch Ophthalmol. 2004;122: 151-156.

28. Ang RT, Dartt DA, Tsubota K. Dry eye after refractive surgery. Curr Opin Ophthalmol. 2001;12:318-322.

29. Donnenfeld ED, Ehrenhaus M, Solomon R, et al. Effect of hinge width on corneal sensation and dry eye after laser in situ keratomileusis. J Cataract Refract Surg. 2004;30:790-797.

30. Miljanović B, Trivedi KA, Dana MR, et al. Relation between dietary n-3 and n-6 fatty acids and clinically diagnosed dry eye syndrome in women. Am J Clin Nutr. 2005;82:887-893.

31. Schlote T, Kadner G, Frudenthaler N. Marked reduction and distinct pattern of eye blinking in patients with moderately dry eyes during video display terminal use. Graefes Arch Clin Exp Ophthalmol. 2004;242:306-312.

32. Schindelar MR, Prifogle E, Ouslar GW, et al. Diurnal variations in symptoms of dry eye. ARVO April 27-May 1, Fort Lauderdale, Florida. D761. 2008

33. Wolkoff P, Nøjaard JK, Troiano P, et al. Eye complaints in the office environment: precorneal tear film integrity influenced by eye blinking efficiency. Occup Environ Med. 2005;62:4-12.

34. Wolkoff P, Nøjaard JK, Franck C, et al. The modern office environment desiccate the eye? Indoor Air. 2006;16:258-265.

35. Kjæregaard SK, Hempel-Jørgensen A, Mølhave L, et al. Eye trigeminal sensitivity, tear film stability, and conjunctival epithelium damage in 182-non-allergic, non-smoking Danes. Indoor Air. 2004;14:200-207.

36. Wolkoff P, Kjæregaard SK. The dichotomy of relative humidity on indoor air quality. Environ Int. 2007;33:850-857.

37. Khurana AK, Choudhary R, Ahluwalia BK, et al. Hospital epidemiology of dry eye. Indian J Ophthalmol. 1991;39:55-58.

38. Miljanović B, Dana R, Sullivan DA, et al. Impact of dry eye syndrome on vision-related quality of life. Am J Ophthalmol. 2007;143:409-415.

39. Pflugfelder SC. Prevalence, burden, and pharmacoeconomics of dry eye disease. Am J Manag Care. 2008;14:S102-S106.

40. Schiffman RM, Walt JG, Jacobsen G, et al. Utility assessment among patients with dry eye disease. Ophthalmolmology. 2003;110: 1412-1419.

41. Calculation based on A C Nielsen data through its ScanTrack FDM + 4th Channel Service for the Dry Eye Category for the 52-week period ending $8 / 09 / 08$, for the US market.
42. Wolff E. 1954. Anatomy of the eye and orbit. (4th ed., p. 20-34) New York: Blackstone Co.

43. Foulks GN. Determinants of Tear Film Stability. American Academy of Ophthalmology Annual Meeting, October 15-18, Chicago. The Castroviejo Lecture; 2005.

44. Wilson MW, Dailey RA. Eyelid malposition. In: GA Cioffi (Ed.). The Devers manual: ophthalmology for the health care professional. 1997; Baltimore: Williams \& Wilkins. (p. 27-35).

45. Abelson MB, Ousler GW III, Nally LA, et al. Alternative reference values for tear film break up time in normal and dry eye populations. Adv Exp Med Biol. 2002;506:1121-1125.

46. Abelson MB. Tear substitution. In: Albert DM, Jacobiec FA, Azar DT, Editors. Principles and Practice of Ophthalmology. 2nd ed. Philadelphia: WB Saunders; 1994. p. 1055-1059.

47. Noecker RJ. Comparison of initial treatment response to tow enhanced-viscosity artificial tears. Eye Contact Lens. 2006;32: $148-152$.

48. Murube J, Paterson A, Murube E. Classification of artificial tears: I. Composition and properties. Adv Exp Med Biol. 1998a;438:693-704.

49. Murube J, Murube E, Zhuo C. Classification of artificial tears: II. Additives and commercial formulas. Adv Exp Med Biol. 1998b;438: 705-715.

50. Hardten DR, Brown MJ, Pham-Vang S. Evaluation of an isotonic tear in combination with topical cyclosporine for the treatment of ocular surface disease. Curr Med Res Opin. 2007;23:2083-2091.

51. Greiner JV, Glonek T, Scaffidi R. Evaluation of the first metastable lipid emulsion on symptomatic dry eye patients. Invest Opthalmol Vis Sci. 2005;45, E-abstract 2035/B804.

52. Ousler GW, Michaelson G, Christensen MT. An evaluation of tear film break up time extension and ocular protection index scores among three marketed lubricant eye drops. Cornea. 2007;26:949-952.

53. Sall KN, Cohen SM, Christensen MT, et al. An evaluation of the efficacy of cyclosporine-based dry eye therapy when used with marketed artificial tears as a supportive therapy in dry eye. Eye Contact Lens. 2006;32:21-26.

54. Resatasis ${ }^{\circledR}$. Package Insert. Available at: www.allergan.com/assets/pdf/ restasis_pi.pdf. Accessed November 13, 2008.
Clinical Ophthalmology

\section{Publish your work in this journal}

Clinical Ophthalmology is an international, peer-reviewed journal covering all subspecialties within ophthalmology. Key topics include: Optometry; Visual science; Pharmacology and drug therapy in eye diseases; Basic Sciences; Primary and Secondary eye care; Patient Safety and Quality of Care Improvements. This journal is indexed on Submit your manuscript here: http://www.dovepress.com/clinical-ophthalmology-journal

\section{Dovepress}

PubMed Central and CAS, and is the official journal of The Society of Clinical Ophthalmology (SCO). The manuscript management system is completely online and includes a very quick and fair peer-review system, which is all easy to use. Visit http://www.dovepress.com/ testimonials.php to read real quotes from published authors. 